\title{
A ANTOLOGIA KOKINWAKASHÛ (905) E A FORMAÇÃO DA TRADIÇÃO POÉTICA JAPONESA
}

\section{João Marcelo Monzani* \\ USP \\ joaomarcelo.monzani@gmail.com}

\begin{abstract}
RESUMO: Este trabalho aborda a antologia poética imperial Kokinwakashû, compilada em 905 na corte japonesa. Pretende-se aqui explicitar os princípios que regem a compilação e organização da obra, pois eles tiveram um papel inaugural e fundamental na criação da tradição nipônica de poesia. Especificamente, demonstraremos que os poemas da antologia Kokinwakashû encontram-se elencados de acordo com o princípio da progressão temáticotemporal, ou seja, dentro de um tema maior, os poemas se organizam tendo como eixo seu desenrolar temporal. Para demonstrar o princípio da progressão temático-temporal em funcionamento, optamos por traduzir o "Livro 6, Inverno", da antologia e, em seguida, explicitar os mecanismos que explicam a sequência e encadeamento dos poemas. Por fim, abordamos brevemente o declínio da tradição poética japonesa.
\end{abstract}

Palavras-chave: Kokinwakashû; antologia poética; poesia japonesa

ABSTRACT: This paper intend to be an approach to the Imperial anthology Kokinwakashû, edited in 905 in the Japanese court. We aim at explaining the principles that inform the compilation and organization of the work, since they had a foundational and fundamental role in the creation of Japanese poetic tradition. Specifically, we will show that the Kokinwakashû poems are organized by the principle of a thematic-and-time progression, that is to say, under a certain theme poems are arranged by their calendrical development. To demonstrate such principle, we decide to translate "Book 6, Winter", and also to comment on the mechanisms that explain the sequencing of poems. In the last part of the paper, we trace a brief sketch of the decline of Japanese poetic forms.

Keywords: Kokinwakashû; anthology; Japanese poetry

Graduado em Letras Japonês-Português, Mestrado em Literatura Japonesa e Doutorado em Teoria Literária e Literatura Comparada pela Universidade de São Paulo. Pesquisador. 
Pode-se dizer que a antologia poética Kokinwakashû (Coletânea de poemas japoneses de antanho e de agora, 905), a primeira a ser oficialmente compilada na corte imperial japonesa, é uma das obras fundamentais na formação da tradição literária daquele país. Talvez seja um caso único no mundo em que uma antologia tornou-se tão decisiva no estabelecimento de um campo e uma tradição literária. Mais do que a qualidade dos poemas nela inclusos, a reverência com que a obra continuou a ser lida séculos após a compilação se deve à sua natureza propriamente antológica, ou seja, aos princípios que regem sua organização e seleção. $\mathrm{O}$ Kokinwakashû funciona, como pretendemos mostrar, como um todo integrado, na medida em que a sequência de cada poema, que conduz a uma progressão temático-temporal, é o princípio de organização da obra. Neste artigo pretende-se explicitar esse princípio, através de uma tradução comentada de um de seus tomos, bem como oferecer instrumentos visando a uma iniciação à leitura e apreciação da poesia japonesa. $\mathrm{O}$ cuidado com a seleção e disposição dos poemas fez com que o Kokinwakashû adquirisse o status de um clássico, uma espécie de parâmetro, ou guia, de possibilidades poéticas.

A poesia japonesa continua desconhecida do público ocidental, não obstante seus mais de mil anos de história. Obviamente, a barreira da língua é a grande responsável por tal situação e não há saída simples para esse impasse. Mesmo assim, é possível apreciar suas qualidades estéticas mesmo na tradução, desde que se adquira alguns conhecimentos prévios. Ao explicitar os princípios 
organizacionais da antologia Kokinwakash $\hat{u}$, sua leitura não mais parecerá algo inalcançável. O exercício também vale a título comparativo, pois tanto os poemas como a antologia são governados por regras bastante estranhas à tradição poética ocidental.

Passemos aos dados fundamentais. O Kokinwakashû $\hat{u}^{1}$ é representante máximo daquilo que se convenciona chamar poesia clássica japonesa. Por tal nomenclatura entende-se a poesia escrita antes de 1868, ano de abertura dos portos nipônicos ao contato cultural e comercial irrestrito com o ocidente. Por outro lado, poesia clássica japonesa também significa, de uma maneira talvez inimaginável no ocidente, poesia ligada estritamente à tradição poética da corte imperial. Falar em poética clássica japonesa significa falar na poética criada e oficializada pela corte imperial, com restrições claras quanto à temática, ao vocabulário e à tonalidade. A poesia clássica japonesa não admitia inovação nesses campos, como ficará claro logo abaixo. Uma das obras que estabeleceu tais regras, que só foram abandonadas depois de séculos e sob o impacto da poesia europeia, foi justamente o Kokinwakashû.

O Kokinwakashî é a primeira das chamadas vinte e uma antologias poéticas oficiais da corte, uma vez que a compilação de cada uma delas se deu sob ordem de um imperador, como se pode constatar na tabela abaixo ${ }^{2}$ :

${ }^{1}$ Para este trabalho foi utilizado: KUBOTA, Utsubo (ed.) Kokinwakashû Hyôshaku. Tóquio: Tôkyôdô Shuppan, 1960 (5ª . edição).

${ }^{2}$ Adaptada de: NAKA, Mitsuo. Shinkokugo Benran. Tóquio: Buńeidô, 1998, p. 75. Revista Texto Poético I ISSN: 1808-5385 | Vol. 20 (1o sem-2016) - p. 13 


\begin{tabular}{|c|c|c|c|}
\hline & Nome da antologia & $\begin{array}{c}\text { Data de } \\
\text { entrega ao } \\
\text { trono } \\
\end{array}$ & $\begin{array}{c}\text { Imperador } \\
\text { que ordenou a } \\
\text { compilação }\end{array}$ \\
\hline 1 & Kokinwakashû & 905 & Daigo \\
\hline 2 & Gosenwakashû & 951 & Murakami \\
\hline 3 & Shûiwakashô & 1004-1012 & Kazan \\
\hline 4 & Goshûiwakashû & 1086 & Shirakawa \\
\hline 5 & Kinyôwakashûu & 1127 & Shirakawa \\
\hline 6 & Shikawakashû & 1151 & Sutoku \\
\hline 7 & Senzaiwakashû & 1188 & Goshirakawa \\
\hline 8 & Shinkokinwakashû & 1205 & Gotoba \\
\hline 9 & Shinchokusenwakashû & 1235 & Gohorikawa \\
\hline 10 & Shokugosenwakashû & 1251 & Gosaga \\
\hline 11 & Shokukokinwakashû & 1265 & Gosaga \\
\hline 12 & Shokushûiwakashû & 1278 & Kameyama \\
\hline 13 & Shingosenwakashû & 1303 & Gouda \\
\hline 14 & Gyokuyôwakashû & 1312 & Fushimi \\
\hline 15 & Shokusenzaiwakashû & 1320 & Gouda \\
\hline 16 & Shokugoshûiwakashû & 1326 & Godaigo \\
\hline
\end{tabular}

Revista Texto Poético | ISSN: 1808-5385 | Vol. 20 (1o sem-2016) - p. 14 


\begin{tabular}{|c|c|c|c|}
\hline & Nome da antologia & $\begin{array}{c}\text { Data de } \\
\text { entrega ao } \\
\text { trono }\end{array}$ & $\begin{array}{l}\text { Imperador } \\
\text { que ordenou a } \\
\text { compilação }\end{array}$ \\
\hline 17 & Fûgawakashû & 1345 & Hanazono \\
\hline 18 & Shinsenzaiwakashû & 1359 & Gokôgon \\
\hline 19 & Shinshûiwakashû & 1364 & Gokôgon \\
\hline 20 & Shingoshûiwakashû & 1384 & Goenyû \\
\hline 21 & Shinshokukokinwakashû & 1439 & Gohanazono \\
\hline
\end{tabular}

Além de quase todas as vinte antologias subsequentes ao Kokinwakashû seguirem seu formato (divisão em vinte partes, por tema), elas também adotam o princípio da progressão temáticotemporal como regra de organização de distribuição dos poemas selecionados. Como já foi dito anteriormente, a temática, o vocabulário e a atitude estética refletem as diretrizes adotadas pelo Kokinwakashû. Portanto, entender as bases dessa antologia constitui-se em uma verdadeira iniciação à tradição poética japonesa.

Nossa explicação está dividida em três partes: a poesia japonesa antes das antologias imperiais; os princípios de organização do Kokinwakashû; o abandono dos padrões estabelecidos pelo cânone. Pretende-se, através desses três movimentos, apresentar o surgimento, o estabelecimento e a queda da estética conhecida como poesia japonesa de corte ou poesia clássica. 


\section{A poesia japonesa antes das antologias poéticas imperiais}

Se o Kokinwakashû é considerado a primeira antologia oficial da corte japonesa, uma vez que os documentos comprovam sua comissão pelo imperador Daigo (905), não se pode esquecer da existência do Manyôshû̉ (Coletânea das mil folhas, 770?). Antologia anterior em mais de cem anos quatro vezes mais extensa que a oficial, o Manyôshî é igualmente uma das bases e fontes de inspiração da tradição da poesia nipônica.

Não se sabe a data exata de compilação do Manyôshû, nem as circunstâncias de sua organização. Atualmente acredita-se que se trata de uma antologia de várias antologias menores (agora em grande parte perdidas), organizada pelo poeta Ôtomo Yakamochi (718-785). Não havendo documentos que comprovem sua ligação com o trono, é considerada uma coleção particular, não entrando, portanto, na contagem das 21 compilações imperiais. Mas o motivo principal pelo qual o Manyôshû não entra nessa contagem está no fato de ele destoar por demais da organização temático-temporal do Kokinwakashî.

Os vinte livros do Manyôshû não obedecem a nenhuma ordenação sistemática. Os livros 1 a 6 registram os poemas mais antigos, ordenados por reinados. O livro 4 reúne poemas de temática amorosa (sômon) do século VIII, enquanto o livro 5 chega a incorporar poemas escritos em chinês. Os livros 8 e 10 se ocupam de poemas de temática das quatro estações, enquanto o livro 9 reúne poemas longos (chôka) com temática lendária e de descrição de

${ }^{3}$ Para maiores detalhes: WAKISAKA, Geny. Man'yôshu - vereda do poema clássico japonês. São Paulo: Hucitec, 1992, e FURUHASHI, Nobutaka. Man'yôshû wo yomu. Tóquio: Furukawa Kôbunkan, 2008.

Revista Texto Poético I ISSN: 1808-5385 | Vol. 20 (1o sem-2016) - p. 16 
lugares. Os livros 11 e 12 reúnem poemas amorosos, o livro 13, poemas longos, e o 14, canções das regiões mais afastadas da capital. Os livros restantes parecem ser uma compilação de canções antigas e contemporâneas do já mencionado Ôtomo no Yakamochi. Poemas de um mesmo autor costumam aparecer em bloco.

O caráter extremamente heteróclito dos poemas aí reunidos revela a ausência de um princípio organizacional e talvez aponte para o fato de se tratar da junção de muitas coleções poéticas menores, reunidas sob o nome de Manyôshû. Da mesma forma, as temáticas dos poemas aí reunidos são das mais variadas, indo da descrição de cenas naturais, até canções de guerra, descrição dos negócios de Estado, e da descoberta de ouro. O Kokinwakashû, logo em seguida, iria impor limites a essa variedade.

O Manyôsh û contém cerca de 4.500 poemas (o número podendo variar dependendo do manuscrito que se adota). Há poemas de imperadores e cortesãos, como seria de se esperar, mas também de autoria popular (algo que não se repete nas antologias oficiais). Mesmo dentro da tradição poética japonesa, o Manyôshû conserva uma atmosfera de exotismo, proveniente da antiguidade de sua compilação, do palavreado arcaico e da composição em ritmos simples e paralelos. Todas essas características podem ser verificadas no poema n. 199 (Livro II), da autoria de Kakinomoto no Hitomaro (datas desconhecidas), um dos mais célebres poetas do estilo arcaico. 
Ômimi ni

Tachi oriobashi

Ômite ni

Yumi torimotashi

Miikusa o

Adomoitamai

Totonouru

Tsuzumi no oto wa

Ikazuchi no

Oto to kiku made

Fukinaseru

Kuda no oto mo

Atamitaru

Tora ga hoyuru to

Morobito no

Obiyuru made ni
Nosso divino Príncipe

Guardou sua espada

Em seu cinto

E pegou seu arco

Com um grito de batalha

Incentivou as tropas

Por entre as fileiras de soldados

O som do tambor

Ressoava

Como um trovão

Tocava-se

Instrumentos de sopro

Que assemelhavam-se

Ao rugido do tigre

Até os mais valentes

Tremeram de terror ${ }^{4}$

Note-se, em primeiro lugar, uma constante: a alternância sistemática de versos de 5 e 7 sílabas (com) apenas uma exceção, kuda no oto mo). Mais do que o padrão básico, essas são as duas únicas medidas básicas do verso japonês. Perguntar-se o porquê dessa métrica seria entrar em questões de origem do ritmo poético, sua ligação com o canto popular e o ritmo do trabalho, temas que não abordaremos aqui. Interessa mais notar que toda a poesia japonesa clássica é escrita com a alternância de versos de 5 e 7 sílabas. Tal constante só foi modificada no fim do século XIX, por influência do verso livre europeu.

${ }^{4}$ OMODAKA, Hisakata. Manyôshû Chûshaku Dainikan. Tóquio: Chûôkôronsha, 1968, p. 369-407. A tradução é minha, baseada nos comentários de Omodaka Hisakata. 
O Manyôsh û ainda admite certa flexibilidade quanto ao número de sílabas totais que um poema pode possuir: o chôka de extensão indefinida (é o nosso exemplo), o katauta de 19 sílabas, o sedôka de 38 e o tanka de 31. Eis aí uma das grandes diferenças entre o Manyôshû e o Kokinwakashû: enquanto a primeira coleção admite uma grande variedade de formas poéticas, o Kokinwakash $\hat{u}$ estabeleceu, definitivamente, a forma poética como sendo o tanka, o poema de 31 sílabas, divido em unidades silabares de 5-7-5-7-7. Por exemplo:
$\mathrm{Ki} / \mathrm{mi} / \mathrm{na} / \mathrm{ra} / \mathrm{de}(5)$
Ta/re/ni/ka/mi/se/n (7)
U/me/no/ha/na (5)
I/ro/o/mo/ka/o/mo (7)
Shi/ru/hi/to/zo/shi/ru $(7)^{5}$

Se não para você,/ para quem mostrarei/ essa flor de ameixa? /Apenas aqueles que de fato conhecem podem apreciar/ sua beleza e fragrância, (Kokinwakashû I,38)

Quando se diz que o Kokinwakashû estabeleceu os padrões da poesia clássica japonesa, isso significa, em primeiro lugar, que ele estabeleceu uma forma: 31 sílabas, subdivididas em 5 unidades de respectivamente 5, 7, 5, 7 e 7 sílabas. Poemas que não se encaixavam nesse formato, como o que citamos acima, simplesmente eram considerados como destoantes da tradição. Poemas de extensão diferente, claro, continuaram a ser compostos, mas com a mesma intenção dos poemas em latim na Europa da Idade Moderna - como um passatempo elegante desconectado da corrente poética viva.

${ }^{5}$ Todas as citações do texto original do Kokinwakashû são provenientes de KUBOTA (1960).

Revista Texto Poético | ISSN: 1808-5385 | Vol. 20 (1o sem-2016) - p. 19 


\section{Os princípios de organização do Kokinwakashû}

Um dos princípios básicos da organização do Kokinwakashû já foi explicitado acima: ele reúne majoritariamente tanka, ou seja, poemas de 31 sílabas. As formas de extensão destoantes estão reunidas no Livro 19, que contém um total de sessenta e oito poemas. Nas vinte antologias imperiais sucessivas, esse número é ainda mais reduzido, atestando o domínio absoluto do tanka como forma poética por excelência.

O que diferencia o Kokinwakashû das coleções poéticas anteriores, mais do que tudo, é o extremo cuidado na seleção e organização dos poemas. A preocupação dos compiladores em criar uma estrutura orgânica, com início, meio e fim, é palpável. Cada poema está onde está por um motivo. Os vinte livros que compõem o Kokinwakashû estão divididos por tema, e dentro de cada livro a progressão de um poema para o outro foi meticulosamente pensada. Os vinte livros dividem-se nas seguintes categorias:

\begin{tabular}{|l|c|}
\hline \multicolumn{1}{|c|}{ Livro } & Número de Poemas \\
\hline Primavera (I) & 68 \\
\hline Primavera (II) & 66 \\
\hline Verão & 34 \\
\hline Outono (I) & 80 \\
\hline Outono (II) & 65 \\
\hline
\end{tabular}




\begin{tabular}{|c|c|}
\hline Livro & Número de Poemas \\
\hline Inverno & 29 \\
\hline Felicitações & 2 \\
\hline Separações & 41 \\
\hline Viagens & 16 \\
\hline Jogos de palavras & 47 \\
\hline Amor (I) & 83 \\
\hline Amor (II) & 64 \\
\hline Amor (III) & 6um \\
\hline Amor (IV) & 70 \\
\hline Amor (V) & 82 \\
\hline Tristeza & 34 \\
\hline Vários (I) & 70 \\
\hline Vários (II) & 68 \\
\hline Formas miscelâneas & 68 \\
\hline Poemas de ritual & 32 \\
\hline
\end{tabular}

Logo nota-se que os dois principais temas da antologia são as estações do ano e o amor. Esses se tornarão os assuntos quase que 
exclusivos da poesia japonesa doravante, em detrimento de muitos outros. Enquanto o Manyôshû tratava, como mencionamos, de cenas de batalha e guerra, por exemplo, a poética estabelecida pelo Kokinwakashû categoricamente excluía esses assuntos, e muitos outros mais: o cotidiano, o dinheiro, a política, o trabalho, a vida doméstica. Esses passaram a ser tópicos considerados não poéticos, proibidos, portanto. Esse tabu só foi realmente quebrado no século XX. Note-se que o poema do Manyôsh û traduzido anteriormente, por exemplo, não seria selecionado para o Kokinwakashû, em virtude de sua temática.

O prestígio, portanto, do Kokinwakashû como o cânone insuperável da poesia japonesa era imenso. Tanto a forma quanto os tópicos aceitáveis como poesia foram definidos por essa antologia, e compor poesia, no sistema literário japonês, significava conformar-se a essas regras. Os editores do Kokinwakashû apenas selecionaram poemas com vocabulário puramente japonês, criando assim uma terceira regra: a proibição de vocábulos de origem chinesa, regra essa mantida até o fim da tradição dita clássica.

Passemos agora aos princípios propriamente ditos, ou seja, aos princípios que regem a distribuição dos poemas na sua presente ordem.

Os livros que se ocupam das quatro estações se organizam de acordo com a ordem natural (primavera, verão, outono, inverno) e refletem os rituais sazonais da corte japonesa. O primeiro livro da antologia, com poemas de primavera, acompanha detalhadamente o desenrolar da estação, desde a neve remanescente do inverno anterior (no primeiro mês da estação) até o desabrochar das rosas (no terceiro mês). Em levantamento já realizado (RODD, 1984, p. 
25), os poemas de primavera do Kokinwakashî apresentam a seguinte sequência de tópicos:

Primeiro mês da primavera

Começo da primavera

Neve de primavera

Tordo da montanha

Ervas primaveris

Névoa

Folhagem

Chorão

Pássaros

Gansos

Flores de ameixa

Segundo mês da primavera

\section{Cerejeira}

Terceiro mês da primavera

Glicínia

Rosa

Lamentos pela primavera
Número de Poemas

Os poemas contidos nos dois livros de primavera são de diversos autores e épocas. O que define sua ordem e sequência, portanto, não é a cronologia de composição nem a autoria. Os poemas são selecionados e posicionados de acordo com a evolução sazonal da primavera. Além disso, cada poema introduz imagens e associações verbais que serão refletidas nos poemas seguintes.

A organização dos livros que tratam da primavera foi apresentada acima. O "Livro 3, Verão" centra-se basicamente sobre 
um pássaro chamado hototogisu, que canta durante essa estação. É uma seção curta, pois essa não era uma estação considerada particularmente poética. Os livros de Outono e de Inverno trazem, como seria de esperar, imagens associadas ao mundo natural: lua, orvalho e gansos para o primeiro, e neve para o segundo.

O "Livro 7, Felicitações" reúne poemas dedicados a membros da Família Imperial e da alta aristocracia. São poemas de natureza mais formal e celebratória. O livro 9 reúne poemas de separação, organizados pelo princípio da distância percorrida, do mais longe ao mais perto: a China, o exílio, as províncias próximas da capital, excursões em regiões adjacentes ao palácio.

O "Livro 10, Jogos de palavras" recolhe poemas conhecidos como kakushidai, poemas de tópica escondida. A palavra-chave do poema está escondida por entre as 31 sílabas e é preciso procurá-la. Os livros 11 a 15 constituem talvez a parte mais interessante da antologia: os poemas de amor, organizados pelo desenvolvimento típico do relacionamento amoroso da aristocracia da época. O livro 11 reúne poemas sobre a pessoa que ainda não se encontrou - na sociedade de corte, a fama da pessoa era o suficiente para desencadear paixões. O livro seguinte recolhe poemas sobre um amor que se deseja manter escondido, principalmente de seu objeto, por medo de rumores e sofrimento. O livro 13 já se passa depois da consumação amorosa da primeira noite, quando o homem deve voltar para sua casa. Dessa primeira separação temporária nasce a ansiedade da separação permanente que dominará o livro 14 . O último livro de amor, 15, reúne poemas de amargura pós-separação e/ou traição.

Os poemas de luto são elegias e os dois livros seguintes recolhem poemas de tópica indefinida. O livro 19 reúne poemas de 
extensão diferente das 31 sílabas normalmente utilizadas. O último livro é uma coleção de poemas utilizados em rituais da corte.

Dentro de cada livro, como se verá através da tradução abaixo, os compiladores do Kokinwakashû tiveram cuidado de evitar a monotonia, selecionando poemas por tema, tópico e imagística. Em seguida, reuniram poemas que ecoam uns aos outros, seja por progressão temporal (um poema que trata da noite depois de um sobre a manhã, por exemplo), seja por vocabulário ou técnica poética. As marcas da seleção são palpáveis por todo o livro e criaram os padrões contra o qual foi composta e avaliada toda a poesia clássica posterior.

Para ilustrar o funcionamento do Kokinwakashû enquanto antologia organizada, proponho abaixo a tradução, seguindo a ordem de aparição, de vinte e um poemas (de um total de 29) do "Livro 6, Inverno". Mais do que analisar os poemas em detalhe, pretendo chamar a atenção para o seu funcionamento enquanto unidade, e demonstrar a progressão temático-temporal.

Os vinte e nove poemas do livro de inverno são comumente numerados de 314 a 342. Apresento-os traduzidos abaixo, de acordo com a sua ordem no Kokinwakashû:

\section{Kokinwakash û (905) \\ "Livro 6 - Inverno"}

\section{4}

Rio (Montanha) Tatsuta: as chuvas do mês kannazuki tecem um brocado, em linhas verticais e horizontais, sobre a folhagem outonal ${ }^{6}$

${ }^{6}$ Como dissemos anteriormente, o poema japonês comporta sílabas. Mesmo para a língua japonesa, que é bastante concisa, é muito pouco para se dizer algo mais que uma

Revista Texto Poético I ISSN: 1808-5385 | Vol. 20 (1o sem-2016) - p. 25 
Por ser por demais pura, a luz da lua no céu congelou as águas do lago que estavam a fitar-lhe

\section{8}

Que caia sem parar, essa neve branca, até que os talos da planta sussuki em meu jardim dobrem com seu peso

\section{9}

A neve deve estar derretendo assim que toca o chão - nas montanhas o som das cataratas só faz aumentar

\section{0}

As folhas de outono fluem na correnteza desse rio - no fundo das montanhas a neve derretida acrescenta volume às águas

\section{1}

Aqui, na antiga capital, o monte Yoshino está muito perto - não há dia em que a neve não caia

oração, ou, com algum esforço, duas. Optamos por traduzir esses versos na forma de frases em prosa, sem nenhuma tentativa de recriação poética. A maioria dos tradutores de poesia japonesa para o inglês faz exatamente isso, disfarçando, porém, sua escolha na divisão aleatória da frase em 5 estrofes. No nosso caso, equivaleria à tentativa forçada de tornar nossa tradução em poesia pelo recurso da disposição na página:

Rio (Montanha)Tatsuta :

as chuvas do mês kannazuki

tecem um brocado,

em linhas verticais e horizontais,

sobre a folhagem outonal

Não vejo nada que justifique tal disposição no papel do verso traduzido. 
Ao redor da minha casa a neve caiu e cobriu o(s) caminho(s) - não há ninguém que abra uma vereda por ela

\section{3}

Quando neva, a grama e as árvores, que hibernam no inverno, abrem flores desconhecidas da primavera

\section{4}

Quando toda a paisagem está completamente coberta de neve, até as rochas parecem produzir flores

\section{6}

A neve que cai na costa da praia se assemelha à crista das ondas que bate contra Suenomatsuyama

\section{7}

Desde que adentrou, abrindo seu caminho pela neve, na brancura do monte Yoshino, ele não mandou notícias sequer

\section{8}

A neve branca cai e se acumula na montanha - seus moradores devem sentir uma intensa desolação

\section{9}

Nesse caminho coberto de neve e por onde ninguém passa, não há mais nenhum traço (do que houve antes)

\section{0}

Apesar de inverno, do céu caem flores / para além das nuvens deve estar (escondida) a primavera 


\section{1}

Na dormência do inverno, deparo-me com flores que se abrem por entre as árvores - caiu neve

\section{3}

Que ela caia mais uma vez antes que derreta - quando as névoas da primavera surgirem, a neve tornar-se-á uma rara visão

\section{4}

Agora é impossível enxergar as flores de ameixa, pois a neve cobriu todo o céu de branco

\section{5}

A cor das flores mistura-se à neve e torna-se invisível flores, exalem sua fragrância!, para que pessoas possam encontrá-las

\section{6}

Se o perfume da flor de ameixeira se misturar à neve, quem seria capaz de distinguir uma da outra?

339

O ano chega ao fim - tanto a neve quanto o meu tempo só fazem acumular

\section{2}

$\mathrm{O}$ ano que chega ao fim deixou um gosto amargo - o reflexo que passa pelo espelho logo se apaga 
O poema 314 abre a seção de inverno: ele ainda faz menção à estação anterior, o outono, através da alusão do brocado de folhas. Já a chuva mencionada (shigure) é uma palavra associada ao início do inverno. O poema tem a função, portanto, de realizar a transição entre o "Livro 5, Outono" e o presente "Livro 6, Inverno", utilizando duas imagens centrais (folhas e chuva), uma de cada estação. $\mathrm{O}$ poema nasce de uma visão antropomórfica: a chuva do mês de kannazuki (corresponde ao décimo mês no calendário lunar) tece um brocado de folhas de outono. Os comentadores da edição Shôgakkan (OZAWA, 1994, p. 159) parecem certos que se deve trocar Tatsutagawa (rio Tatsuta) por Tatsutayama (montanha Tatsuta), para dar sentido ao poema - "a chuva cobre a montanha com traços verticais e horizontais, dando a aparência de brocado à folhagem outonal".

O poema seguinte, 316, segue a técnica da antropomorfização. O lago transforma-se num imenso olho que observa a luz gélida da lua. Além disso, introduz a temática da água, que será retomada em 319 e 320 . O poema também é importante, pois indica a sequência de pequenas cenas que vão, em conjunto, apresentando a paisagem do inverno. Aqui se trata de um lago congelado, apresentado através do recurso retórico de que foi a luz da lua, e não o frio, que causou o fenômeno. As ideias de brancura (luz da lua) e translucência serão igualmente mantidas durante todo o livro.

O 317 (não traduzido aqui) faz a primeira menção de neve, tópico mantido até o poema 337, sendo, portanto, o grande assunto do "Livro 6, Inverno". O 318 apresenta o desejo do eu-lírico de que a neve caia com mais imensidade, a ponto de dobrar os talos das plantas sussuki. Nota-se, portanto, que ainda estamos no início do 
inverno e a neve é fraca. Os poemas 319 e 320 mantém essa tópica, ambos trabalhando a imagem da neve que derrete ao contato com o solo e/ou a água. Em 319, a neve derretida aumenta a corrente da água, causando barulho e, em 320, o aumento de águas causa maior velocidade na corrente. Ambos os poemas apresentam cenas mais dinâmicas e movimentadas de inverno, por oposição a 321-324, de cenas mais estáticas e solitárias.

A partir do poema 321, o inverno se torna mais rigoroso, pois há neve todos os dias. O poema 322 introduz um tópico que se tornará doravante típico em toda a tradição poética japonesa, qual seja, o do isolamento no inverno. No próprio "Livro 6, Inverno", esse tópico é retomado em 327-329.

O 323 e o 324 estão reunidos por utilizarem-se de um mesmo recurso retórico, qual seja, o de apresentar a neve como uma flor. $\mathrm{O}$ poeta assim finge confundir um fenômeno por outro, atitude estética muito típica do Kokinwakashû e considerada de grande elegância por demostrar inteligência e sensibilidade. O 326, logo abaixo, lança mão deste mesmo recurso, dessa vez confundindo neve e espuma das ondas. O mesmo recurso será retomado nos poemas 334-337 como mencionaremos abaixo.

Os 327-329 tratam da sensação de isolamento durante o inverno, como já mencionamos. Cada poema, porém, trata o tema de um ângulo diferente, com técnicas que vão da afirmação direta (327) até a especulação existencial (329). O 327 poderia ser tratado, sem dúvida alguma, como um poema de amor. Ele afirma de forma direta e clara o sentimento de seu eu-lírico: o/a amado/a foi-se embora e não mais mandou notícias. O poema utiliza-se da imagem do/a amante andando pela neve virgem para expressar a solidão do eulírico. A neve é aludida enquanto shirayuki, ou seja, neve branca, 
retomando o tópico da brancura recorrente nesse livro. Já o 328 parece ser um poema mais impessoal, pois o eu-lírico apenas alude à sua sensação de isolamento através da menção dos moradores das montanhas cobertas de neve. O poema não é nem tão direto quanto o 327, nem tão abstrato quanto o 329, realizando portanto a passagem do palpável ao filosófico. Suas últimas sílabas (omoi kiyu ran) são idênticas às últimas sílabas do poema seguinte.

O 329 é um poema bastante conhecido na poética japonesa e pode servir de exercício de leitura da poesia daquele país. Ele opera uma modalidade típica nessa literatura: o de dizer, simultaneamente, duas coisas distintas. Ou melhor, a de ter um significado de face que oculta uma segunda significação, que pode ser abstraída da cena real retratada. Retomemos o poema: "Nesse caminho/ coberto de neve/ e por onde ninguém passa,/ não há mais nenhum traço/ (do que houve antes.)" No original: "yuki furite / hito mo kayowanu/michi nare ya/ atohakamonaku / omoi kiyu ran. " À primeira vista trata-se da descrição, direta até, de uma cena natural: a neve encobriu todos os caminhos de acesso ao eu-lírico e apagou todas as marcas do fluxo de pessoas. $\mathrm{O}$ sentimento de isolação é intenso - é isso que o poema aparenta dizer, e diz, em um primeiro momento.

Um jogo de palavras, porém, altera essa configuração: Atohakamonaku pode ser entendido em dois sentidos. O primeiro, que dá a leitura de base do poema, é a que já oferecemos - sem deixar traços. $\mathrm{O}$ segundo sentido dessa expressão, mais comum na forma ato-hakanaku, significa de forma efêmera, passageira. Esse segundo significado das palavras altera por completo a leitura original: "Esse caminho é igual à minha vida./ Por aqui, ninguém passa (me visita)./ Será que vou me apagar,/ efemeramente,/ como a neve apagou os caminhos, sem deixar marcas?". 
O exercício de leitura da poesia japonesa consiste, em grande parte, em perceber esses jogos verbais que duplicam (ou até multiplicam) o sentido dos versos. É a maneira que a poesia japonesa encontrou para superar a sua extrema brevidade, qual seja, a potencialização de significados através de jogos sonoros e verbais.

Em 330, doze poemas antes do final da seção de inverno, portanto, já há o início da transição para a próxima estação, a primavera. Ele é um indício de que a coletânea de poemas de inverno aproxima-se de seu fim. Novamente, a técnica empregada é a da metáfora entre neve e flores que caem do céu. A mesma técnica, por sinal, utilizada em 331, o que atesta para a verdadeira predileção dos poetas da era do Kokinwakashû por tal recurso.

O poema 333 continua na antecipação da próxima primavera, porém exprime o desejo de que mais neve caia, pois não será possível ver tal fenômeno na estação mais quente. $\mathrm{O}$ verbo colocado no imperativo (mata mo furishike, caia mais uma vez) indica que o falante tem consciência de que há tempo para apenas uma nova grande nevasca antes do inverno acabar. Isso justifica a colocação do poema nas partes finais do "Livro 6, Inverno".

Os poemas 334, 335 e 336 estão traduzidos em conjunto para explicitar mais um dos princípios de organização de nossa antologia: a junção de versos que se utilizam de uma mesma imagem, no caso, a confusão entre neve e flores de ameixeira. Como sempre, contudo, os compiladores foram extremamente cuidadosos a fim de evitar a monotonia: o 334 é um poema visual, apelando para a confusão entre neve e flores, transformando os dois em um imenso "mundo de branco". Já o poema 335 acrescenta o elemento da fragrância (o olfato, portanto) ao visual: nesse mundo de brancura só é possível encontrar as flores através de seu perfume. O 336 continua na mesma 
chave, invertendo a ordem: sem o cheiro das flores (elemento olfativo) seria impossível distinguir flor e neve (elemento visual).

Os 339 e 342, últimos poemas do livro de inverno, fecham o conjunto no tom de lamentos pela estação e, por extensão, pela vida que acaba de passar. O sentimento de passagem do tempo, que até então pertencia ao reino do natural, é trazido para a esfera da experiência humana, unindo homem e ambiente. Essencial nessa junção de mundo humano e do natural é o jogo verbal: ambos os poemas utilizam-se de palavras de sentido duplo (furi, cair da neve e envelhecer; kurenu, passar do tempo e apagar-se) para referir-se à unicidade do fenômeno temporal. 342 põe fim aos poemas de estações e é seguido pelo "Livro 7, Felicitações", poemas congratulatórios para membros da família imperial.

Enquanto alguns poemas, como o 330 , se prestam à análise mais detalhada de suas camadas de sentido, a maioria dos poemas do livro de inverno constitui-se em afirmações diretas e/ou jogos de imagem bastante simples. Como dissemos no início desse artigo, o valor dos poemas do Kokinwakashû está mais no seu funcionamento em conjunto, no seu impulso antológico, do que em cada poema isolado.

Como já afirmamos, o Kokinwakashû tornou-se como que a fonte da tradição poética japonesa. Os temas dos poemas de inverno, por exemplo, ficaram restritos, em grande parte àquilo que vimos: passagem da estação, neve derretida no início do inverno, o acúmulo de neve, a solidão e a confusão entre neve e flores. Foram precisos séculos para que novas imagens e novos tópicos adentrassem a poesia japonesa, como ver-se-á brevemente em seguida. 


\section{O abandono dos padrões estabelecidos pelo cânone}

Os padrões estabelecidos pelo Kokinwakashû só começaram a ser descartados no século XV, quando das primeiras manifestações que iriam levar ao surgimento da forma poética conhecida como haikai. Mais precisamente, foi com o surgimento do gênero conhecido como haikai-no-renga, verso conectado cômico, que o cânone poético clássico sofreu seus maiores golpes.

Durante o período Chûsei (1192-1603, equivalente a uma Idade Média japonesa), surgiu a forma literária do renga, traduzido comumente como verso conectado. Dado que o típico poema japonês possuía 31 sílabas, o renga consiste em, primeiramente, separar o poema em duas partes: a primeira de 17 sílabas e a segunda com as 14 restantes. A primeira parte era composta por um poeta mais experiente e a segunda era completada (conectada, daí seu nome) por um segundo poeta. Trata-se de um exercício de composição em conjunto. Aos poucos, aumentou-se o número de poetas participantes e de conexões possíveis. Minase Sangin Hyakuin (Cem versos de três poetas em Minase, 1488) foi composto por três poetas e reúne cem versos.

Nas mãos do poeta Sôgi (1421-1502), o renga atingiu seu ápice. Entretanto, juntamente com seu apogeu, adquiriu uma complexidade de composição muitas vezes maior que a do próprio Kokinwakashû. Para se ter uma ideia da complexidade envolvida, podemos citar alguns dos princípios básicos de composição do renga (MINER, 1979, p. 65) de acordo com Sôgi: se o primeiro verso de uma sequência mencionasse a primavera e o mês mutsuki (o primeiro mês do ano no calendário lunar), por exemplo, o segundo verso também deveria mencionar mutsuki e terminar em substantivo; o terceiro verso deveria terminar em -te, a não ser que essa sílaba já tivesse 
sido utilizada no segundo; nesse caso dever-se-ia usar -ni, -ran ou monashi; o quarto verso deveria evitar referências diretas às estações para servir de transição e o quinto, necessariamente, mencionaria a lua; consequentemente o sexto e sétimo versos seriam sobre o outono, pois a lua é um tópico outonal na tradição poética japonesa. As regras se estendiam para muito além desse breve resumo.

Conforme as regras do renga foram se tornando mais elaboradas e inacessíveis, os poetas mais jovens, sem esperança de competir com os mestres e insatisfeitos com os maneirismos à la Sôgi, passaram a escrever renga humorístico, ou seja, renga que não se preocupava em seguir as regras e que tinha uma tonalidade no geral mais leve. Deram a essa composição o nome de haikai-norenga.

As primeiras coleções de haikai-no-renga realizavam muitas mudanças no campo da prática poética. Em primeiro lugar, aceitavase o uso de palavras chinesas e de coloquialismos japoneses na composição, algo totalmente impensável na tradição do Kokinwakashû. Além disso, o haikai-no-renga estava associado, esteticamente falando, à ideia de gracejo verbal e leveza de tom.

Para se ter uma ideia da iconoclastia dos poetas do haikai-norenga, podemos citar o seguinte poema do século XVI:

Kasumi no koromo susowa nurikeri saohime no haru tachinagara shito shite

Vestes umedecidas pela névoa - quando começa a primavera, a deusa Saohime urina de pé 
Era uma convenção da poesia clássica que a deusa da primavera, Saohime, tinha por veste (koromo) a névoa do início da primavera. $\mathrm{O}$ verso parodia essa tradição ao atribuir a umidade (nurikeri) de suas vestes ao fato de a deusa estar urinando de pé. Há ainda um jogo verbal na palavra tatsu, pois significa tanto que ela está de pé, quanto que a primavera está começando. Obviamente, gracejos com os deuses ou a mera menção de urina seriam práticas inacessíveis na poética do Kokinwakashû.

Assim foi a revolta de jovens poetas contra a rigidez do sistema literário japonês, que lançou as bases para a quebra dos padrões estabelecidos séculos antes, através do acúmulo de sucessivas escolas e antologias poéticas. O haikai-no-renga e, mais tarde, o haikai, abandonam a temática restrita do tanka tradicional e se dedicaram a captar aspectos da existência cotidiana, da vida material e até mesmo do escatológico. O uso vocabular foi ampliado, sendo aceitas palavras de tradição popular ou chinesa. Por fim, as experimentações estéticas se multiplicaram, não se restringindo ao maravilhamento diante do mundo natural típico do Kokinwakashû.

Procuramos nesse breve trabalho apresentar o momento anterior ao surgimento da dita poesia clássica japonesa, bem como seu funcionamento dentro das antologias poéticas e o fim de sua estética. Trata-se de apontamentos inicias, que esperamos servir de apoio para aqueles que venham a se interessar pela e dedicar-se à leitura desse campo literário ainda muito desconhecido de nós. 
Referências

FURUHASHI, Nobutaka. Manyôshû wo yomu. Tóquio: Furukawa Kôbunkan, 2008.

KUBOTA, Utsubo (ed.) Kokinwakashû Hyôshaku. Tóquio: Tôkyôdô Shuppan, 1960 ( $5^{a}$. edição).

MINER, Earl. Japanese linked poetry - an account with translations of renga and haikai. Princeton: Princeton University Press, 1979, p. 65.

NAKA, Mitsuo. Shinkokugo Benran. Tóquio: Bun'eidô, 1998, p. 75.

OMODAKA, Hisakata. Man'yôshû Chûshaku Dainikan. Tóquio: Chûôkôronsha, 1968, p. 369-407.

OZAWA, Tadao (ed.). Kokinwashû. Tóquio: Shôgakkan, 1994, 159.

RODD, Laurel. Kokinshu - a collection of poems ancient and modern.

Princeton: Princeton University Press, 1984, p. 25.

WAKISAKA, Geny. Man'yôshu - vereda do poema clássico japonês. São Paulo: Hucitec, 1992. 